\title{
Comparative proteomic analysis of ductal and lobular invasive breast carcinoma
}

\author{
N.C.S. Oliveira', T.H.B. Gomig ${ }^{1}$, H.H. Milioli' ${ }^{1}$, F. Cordeiro ${ }^{2}$, G.G. Costa', \\ C.A. Urban ${ }^{3}$, R.S. Lima ${ }^{3}$, I.J. Cavalli' ${ }^{1}$ and E.M.S.F. Ribeiro' ${ }^{1}$
}

1'Departamento de Genética, Universidade Federal do Paraná, Curitiba, PR, Brasil 2Departamento de Bioquímica e Biologia Molecular, Universidade Federal do Paraná, Curitiba, PR, Brasil

${ }^{3}$ Unidade da Mama, Hospital Nossa Senhora das Graças, Curitiba, PR, Brasil

Corresponding author: E.M.S.F. Ribeiro

E-mail: eribeiro@ufpr.br

Genet. Mol. Res. 15 (2): gmr.15027701

Received September 22, 2015

Accepted November 26, 2015

Published April 4, 2016

DOI http://dx.doi.org/10.4238/gmr.15027701

\begin{abstract}
Breast cancer is the second most common cancer worldwide and the first among women. Invasive ductal carcinoma (IDC) and invasive lobular carcinoma (ILC) are the two major histological subtypes, and the clinical and molecular differences between them justify the search for new markers to distinguish them. As proteomic analysis allows for a powerful and analytical approach to identify potential biomarkers, we performed a comparative analysis of IDC and ILC samples by using two-dimensional electrophoresis and mass spectrometry. Twenty-three spots were identified corresponding to 10 proteins differentially expressed between the two subtypes. ACTB, ACTG, TPM3, TBA1A, TBA1B, VIME, TPIS, PDIA3, PDIA6, and VTDB were upregulated in ductal carcinoma compared to in lobular carcinoma samples. Overall, these 10 proteins have a key role in oncogenesis. Their specific functions and relevance in cancer initiation and progression are further discussed in this study. The identified peptides represent promising biomarkers for the differentiation of ductal and lobular breast cancer subtypes, and for future interventions based on tailored therapy.
\end{abstract}

Key words: Breast cancer; Histological subtypes; Proteomics; Biomarker 
N.C.S. Oliveira et al.

\section{INTRODUCTION}

Breast cancer is a complex and multifactorial disease that shows wide clinical and histopathological variability. Its etiology is influenced by both endogenous and exogenous factors. Invasive ductal carcinoma (IDC) and invasive lobular carcinoma (ILC) are the most common histological types of breast cancer, respectively ranging from 47 to $79 \%$ and 2 to $15 \%$ of all cases (Zhao et al., 2004). These tumor types have distinct microanatomical origins, contradicting the initial assumption of a common origin in the terminal duct, and the histological differences between the two types result from their individual molecular profiles (Hanby, 2005). Remarkably, ILCs are mainly estrogen receptor (ER) and progesterone receptor-positive, and HER2 and p53-negative (Zhao et al., 2004). On the other hand, ILCs are less cohesive than are IDCs in terms of clinical markers, and they have been associated with the loss of expression of E-cadherin (CDH1) (Berx et al., 1995). Although ILC tumors are of a lower grade in comparison to IDCs, they metastasize to distant sites such as bone, gastrointestinal, peritoneal and ovarian tissues, and are less responsive to neoadjuvant treatment (Hanby and Hughes, 2008).

Despite recent advances in the early detection and molecular classification, and despite improved disease prognosis, there is an urgent need to identify markers capable of differentiating the tumor types to delineate group-based therapy. Several studies have investigated the differential gene expression profile between the two tumor types (Zhao et al., 2004; Bertucci et al., 2008). However, to date, only one study has adopted a proteomic approach to compare IDCs and ILCs. Surface-enhanced laser desorption ionization mass spectrometry (SELDI-MS) revealed high tumor heterogeneity, resulting in a limited identification of differential proteins and peptides using this method (Traub et al., 2005). Comparative proteomic analysis of primary breast tumors and lymph node metastasis successfully identified recurrent differentially expressed proteins (Milioli et al., 2015). Additionally, proteomic-based research has brought new insights on therapy response (He et al., 2009), HER2 overexpression (Tang et al., 2013), and biomarker discovery in fluids (Whelan et al., 2012). In this report, we compare three IDC and three ILC samples using two-dimensional gel electrophoresis (2-DE) and MS to uncover specific protein biomarkers for each histological type. These findings will help elucidate the molecular profiles underlying breast cancer subtypes evolving along distinct pathways, paving the way for personalized therapy.

\section{MATERIAL AND METHODS}

\section{Sample collection}

This study was approved by the Research Ethics Committee of the Hospital Nossa Senhora das Graças in Curitiba, Brazil. Through surgical procedure, breast tumor tissue was collected from six patients with an average age of $56.17 \pm 7.33$ years. Two independent pathologists confirmed the histological type of the tumor, in addition to other characteristics such as tumor size, grade, and presence of lymph node metastasis (Table 1). After collection, the samples were immediately transferred to the laboratory (Laboratório de Citogenética Humana e Oncogenética, Curitiba, PR, Brazil) and stored at $-80^{\circ} \mathrm{C}$ prior to protein extraction. 
Table 1. Clinical and pathological information for patients.

\begin{tabular}{l|c|l|c|c|l}
\hline Patient code & Age & Histological type & Tumor grade & Lesion size (mm) & Lymph node status \\
\hline CP 630 & 52 & Invasive ductal carcinoma & I & 28 & Positive \\
\hline CP 641 & 58 & Invasive ductal carcinoma & II & 100 & Positive \\
\hline CP 645 & 63 & Invasive ductal carcinoma & II & 16 & Positive \\
\hline CP 585 & 66 & Invasive lobular carcinoma & II & 40 & Positive \\
\hline CP 596 & 50 & Invasive lobular carcinoma & I & 35 & Positive \\
\hline CP 638 & 48 & Invasive lobular carcinoma & II & 70 & Positive \\
\hline
\end{tabular}

Tumor grade I (well differentiated); II (moderately differentiated); size of the lesion is determined by the maximum diameter of the primary breast tumor in $\mathrm{mm}$.

\section{Protein extraction and quantification}

Cell lysis was performed in tubes containing $200 \mathrm{mg}$ tumor tissue and $1 \mathrm{~mL}$ of lysis buffer (7 M urea, $2 \mathrm{M}$ thiourea, $40 \mathrm{mM}$ DTT, 4\% CHAPS, and 0.2\% PMSF). Using an electric homogenizer, the tissue was disaggregated and homogenized, and subsequently ruptured by sonication (Fisher Scientific) at a power of $30 \%$ for 6 cycles of $10 \mathrm{~s}$. Each cycle was intercalated with a 1 -min incubation on ice. After centrifugation $\left(30 \times 3.21 \mathrm{~g}\right.$ for $15 \mathrm{~min}$ at $\left.4^{\circ} \mathrm{C}\right)$, the supernatant containing solubilized proteins was aliquoted in tubes and stored at $-80^{\circ} \mathrm{C}$. The protein concentration was measured using the Bradford method (Bradford, 1976).

\section{2-DE}

The lysate (containing $1 \mathrm{mg}$ protein) was mixed in $250 \mu \mathrm{L}$ rehydration buffer containing: $7 \mathrm{M}$ urea, $2 \mathrm{M}$ thiourea, $2 \%$ CHAPS, $0.5 \%$ immobilized pH gradient (IPG) buffer, $50 \mathrm{mM}$ DTT, and a trace amount of bromophenol blue. After rehydration using Ettan IPGphor II (GE Healthcare), the samples were applied to 13-cm linear IPG strips ( $\mathrm{pH} 4-7)$, which were incubated for $16 \mathrm{~h}$ at $20^{\circ} \mathrm{C}$ and $50 \mathrm{~V}$. Immediately after this process, the first-dimensional separation was performed via isoelectric focusing under the following conditions: $500,800,11,300$, and 13,000 $\mathrm{Vhr}$, achieving 26,400 Vhr. The strips were then treated with equilibration buffer I [50 mM Tris, pH 8.8, $6 \mathrm{M}$ urea, $30 \%(\mathrm{w} / \mathrm{v})$ glycerol, $2 \%(\mathrm{w} / \mathrm{v}) \mathrm{SDS}$, and $50 \mathrm{mg} \mathrm{DTT}]$ and II [50 mM Tris, $\mathrm{pH} 8.8,6 \mathrm{M}$ urea, 30\% $(\mathrm{w} / \mathrm{v})$ glycerol, $2 \%(\mathrm{w} / \mathrm{v}) \mathrm{SDS}$, and $200 \mathrm{mg}$ iodoacetamide] for $30 \mathrm{~min}$ each. Second dimension electrophoresis was performed on $10 \%$ polyacrylamide gels (SDS/PAGE), according to Laemmli (1970), using Hoefer SE 600 Ruby (GE Healthcare). Proteins were visualized by staining with colloidal Coomassie (Westermeier and Naven, 2002).

Three technical replicates were included for each patient, 3 ILCs and 3 IDCs, resulting in a total of 18 gels. We have not removed plasma proteins from the samples. Many studies have used methods for precipitation, centrifugation, and affinity chromatography to remove albumin and immunoglobulin (Chen et al., 2005; Colantonio et al., 2005; Zolotarjova et al., 2005). However, these immunodepletion methods have a limited capacity to bind these profuse proteins; thus, depletion is not complete. In addition, it may restrict the number of identified proteins since other proteins may be removed together to the albumin due its carrier physiologic function (Sutton et al., 2010).

After staining, gels were directly scanned using ImageScanner ${ }^{T M}$ II (GE Healthcare) and analyzed with the ImageMaster ${ }^{\mathrm{TM}}$ 2D Platinum v6.0 software (GE Healthcare). The parameters used for spot detection were as follows: area min -5 ; smooth -3 ; and saliency -25 . Triplicates 
were cropped to frame the same cluster of spots across all samples, and one representative gel was used to create a match-set. In addition, the logarithmic ratios of spots with precise matching were considered for normalization with ImageMaster ${ }^{\mathrm{TM}}$. In order to standardize, the volume of each spot was normalized to the total volume of the detected spots in the gel. These data were analyzed statistically (using the Student $t$-test) and spots with a significant variation $(P<0.05)$ were considered for analysis. Next, the representative IDC gel was compared with the representative ILC gel. Via comparative analysis, protein spots were categorized as upregulated when the spot intensity was at least two folds greater.

\section{Protein identification by peptide mass fingerprinting and tandem MS (PMF and MS/MS)}

All selected spots were manually removed from the gel and transferred to tubes containing $200 \mu \mathrm{L}$ destaining solution (50\% acetonitrile, $25 \mathrm{mM}$ ammonium bicarbonate) for $1 \mathrm{~h}$. The supernatant was removed, and the gel pieces were subjected to two 5-min dehydration steps with acetonitrile. For proteolytic digestion, the spots were rehydrated in $10 \mu \mathrm{L}$ buffer containing 40 $\mathrm{mM}$ ammonium bicarbonate, $10 \%$ acetonitrile and $15 \mathrm{ng} / \mu \mathrm{L}$ trypsin (Sequencing Grade Modified Trypsin; Promega, Fitchburg, WI, USA) in an ice-cold bath for $30 \mathrm{~min}$. The digestion was performed at $37^{\circ} \mathrm{C}$ overnight. The solution containing peptides was mixed (1:1) with $50 \%$ acetonitrile and $0.1 \%$ trifluoroacetic acid saturated with HCCA matrix ( $\alpha$-cyan-4-hydroxinnamic acid) and spotted onto the MALDI AnchorChip target (Bruker Daltonics, Billerica, MA, USA).

The mass of the digested peptides was determined using a MALDI-ToF/ToF/MS/MS Autoflex II (Bruker Daltonics) mass spectrometer. MALDI mass data were externally calibrated with a peptide calibration standard kit. Internal calibration was performed using trypsin autolysis fragments at an $\mathrm{m} / \mathrm{z}$ ratio of 842.50 and $2211.10 \mathrm{Da}$. The analysis and treatment of the spectra were performed using FlexAnalysis 3.0 (Bruker Daltonics).

\section{Protein identification}

Proteins were identified by PMF and MS/MS and compared with the theoretical molecular weight $(\mathrm{MW})$, isoelectric point $(\mathrm{pl})$, and sequence coverage data from UniProtKB/Swiss-Prot using the Matrix Science (MASCOT) database. The search parameters were Homo sapiens for taxonomy, digestion with trypsin enzyme, and peptide tolerance up to $100 \mathrm{ppm}$, with only one missed cleavage site. Oxidation of methionine and carbamidomethylation of cysteine were, respectively, the variable and constant modifications. The protein name and code were obtained through UniProtKB/SwissProt. Proteins were considered reliable when the score exceeded the threshold value of 56 (PMF) or 20 (MS/MS) $(\mathrm{P}<0.05)$, and above four peptides were recognized.

\section{RESULTS AND DISCUSSION}

In this study, we analyzed IDC and ILC samples by 2-DE and one reference gel was chosen from each sample, based on the representation and resolution of the spots. The six reference gels were then analyzed to define the most representative gels (645T2 and 596T1) for each histological type (Figures 1 and 2). After comparison between the representative gels, we matched all of the significant spots among the gels, to ensure reproducibility in all of them (data not shown). We observed a consistent proteomic profile pattern for samples obtained from patients with the same 
tumor subtype. Based on the results obtained using statistical criteria (minimum 2-fold change and $P<0.05$ ), 38 spots with differential expression across the two tumor subtypes were selected for further analysis on the mass spectrometer. Differentially expressed proteins were defined as reliable if the proportional values of $\mathrm{MW}$ and $\mathrm{pl}$, theoretical and observed, were also identified at the expected position on the gels ( $\Delta \mathrm{MW}<20 \%$ and $\Delta \mathrm{pl}<0.6$, according to Dupont et al., 2005).

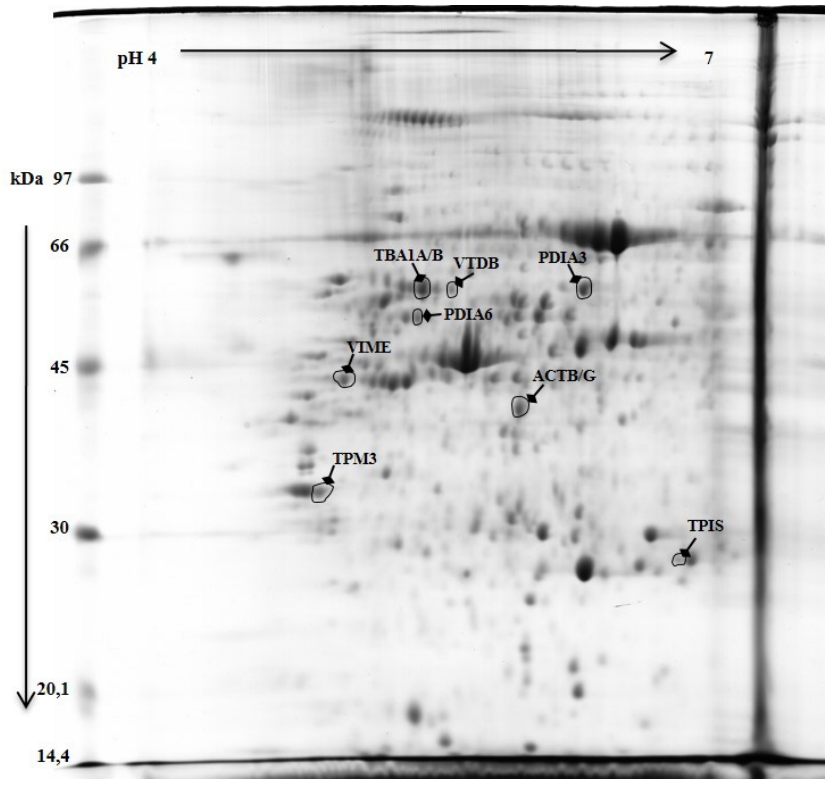

Figure 1. Proteomic profiling of the most representative (master) gel of invasive ductal carcinoma samples. The arrows indicate spots representing differentially expressed (upregulated) proteins.

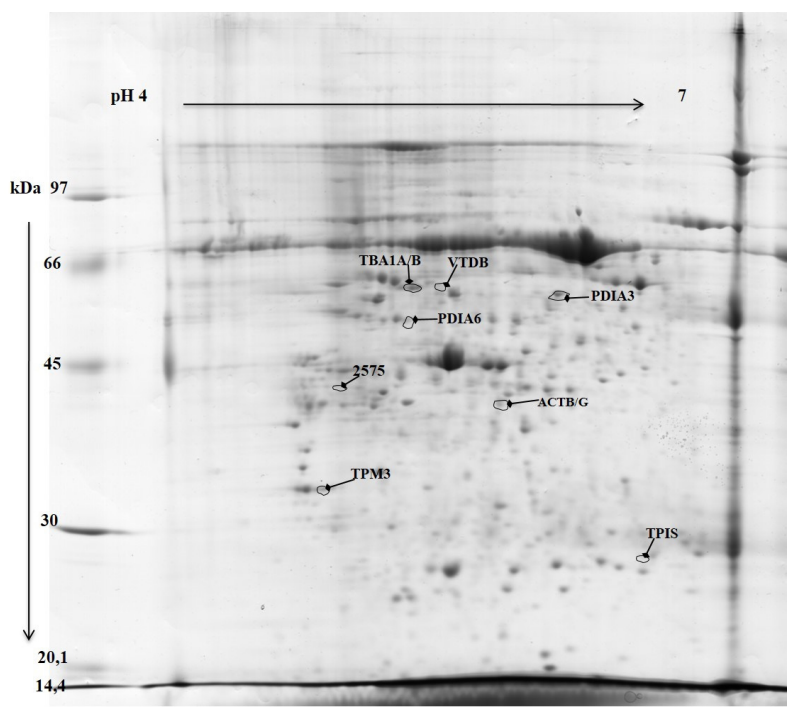

Figure 2. Proteomic profiling of the most representative (master) gel of invasive lobular carcinoma samples. The arrows indicate spots representing differentially expressed (downregulated) proteins. 
Among them, we depicted 23 spots, corresponding to 10 distinct proteins (Tables 2 and 3 ) that showed up- or downregulation when comparing IDC and ILC.

\begin{tabular}{|c|c|c|c|c|c|c|c|c|c|c|}
\hline UniProtKB code & Protein name (Abbreviation) & Spot ID & \begin{tabular}{|l|} 
Fold change \\
\end{tabular} & $P$ value & MASCOT score & Tol. (ppm) & $\begin{array}{c}\text { Theoretical } \\
\mathrm{MW} / \mathrm{pl}\end{array}$ & $\begin{array}{c}\text { Experimental } \\
\mathrm{MW} / \mathrm{pl}\end{array}$ & SC (\%) & \% Masses matched \\
\hline \multicolumn{11}{|l|}{ Structure prote } \\
\hline $\begin{array}{l}\text { Q96HG5 } \\
P 63261\end{array}$ & Actin, cytoplasmic 1 (ACTB) & 886 & 5.06 & $<0.05$ & 70 & 100 & $42.0 / 5.29$ & $40.0 / 5.81$ & 23 & $6 / 17(35 \%)$ \\
\hline $\begin{array}{l}\mathrm{P} 63261 \\
P 06753\end{array}$ & Actin, cytoplasmic 2 (ACTG) & 886 & 5.06 & $<0.05$ & 70 & 100 & $42.1 / 5.31$ & $40.0 / 5.81$ & 23 & $6 / 17(35 \%)$ \\
\hline P06753 & Tropomyosin alpha-3 chain (TPM3) & 995 & 2.07 & $<0.05$ & 83 & 100 & $32.8 / 4.68$ & $33.0 / 4.84$ & 17 & $7 / 11(63 \%)$ \\
\hline Q71U36 & Tubulin alpha-1A chain (TBA1A) & 658 & 2.26 & $<0.02$ & 116 & 100 & $50.7 / 4.94$ & $57.0 / 5.34$ & 30 & $9 / 23(39 \%)$ \\
\hline P68363 & Tubulin alpha-1B chain (TBA1B) & 658 & 2.26 & $<0.02$ & 135 & 100 & $50.8 / 4.94$ & $57.0 / 5.34$ & 33 & $10 / 23(43 \%)$ \\
\hline$\frac{\text { P08670 }}{\text { Metabolism }}$ & Vimentin (VIME) & 834 & 4.69 & $<0.05$ & 188 & 100 & $53.6 / 5.06$ & $43.0 / 4.96$ & 33 & $15 / 19(79 \%)$ \\
\hline Metabolism & Triosephosphate isomerase (TPIS) & 1072 & 2.44 & $<0.05$ & 174 & 40 & $6.9 / 6.45$ & 28.0/6.58 $>20$ - & 60 & $12 / 26(46 \%)$ \\
\hline \multicolumn{11}{|c|}{$\begin{array}{l}\text { Molecular chaperones/heat shock protein } \\
\end{array}$} \\
\hline $\begin{array}{l}\text { P30101 } \\
\text { Q15084 }\end{array}$ & \begin{tabular}{|l|} 
Protein disulfide-isomerase A3 (PDIA3) \\
Protein disulfide-isomerase A6 (PDIA6)
\end{tabular} & $\begin{array}{l}\frac{665}{717} \\
717\end{array}$ & $\begin{array}{l}2.75 \\
2.07\end{array}$ & $\begin{array}{l}<0.001 \\
<0.01\end{array}$ & $\frac{117}{24}$ & $\begin{array}{l}100 \\
100\end{array}$ & $\begin{array}{l}57.1 / 5.98 \\
48.4 / 4.95 \\
\end{array}$ & $\begin{array}{l}57.0 / 6.12 \\
51.0 / 5.28\end{array}$ & 25 & $\frac{13 / 30(43 \%)}{-}$ \\
\hline Transport & & & & & & & & & & \\
\hline P02774 & Vitamin D-binding protein (VTDB) & 666 & 2.68 & $<0.05$ & 60 & 50 & $54.5 / 5.40$ & $56.0 / 5.45$ & 12 & $5 / 13(38 \%)$ \\
\hline
\end{tabular}

\begin{tabular}{|c|c|c|c|c|c|c|c|c|c|c|}
\hline UniProtKB code & Protein name (Abbreviation) & Spot ID & Fold change & $P$ value & MASCOT score & Tol. (ppm) & Theoretical MW/pI & Experimental MW/pl & SC (\%) & $\%$ Masses matched \\
\hline \multicolumn{11}{|c|}{ Structure proteins } \\
\hline Q96HG5 & Actin, cytoplasmic 1 (ACTB) & 2608 & -5.06 & $<0.05$ & 59 & 50 & $42.0 / 5.29$ & $41.0 / 5.76$ & 13 & $4 / 6(66 \%)$ \\
\hline P63261 & Actin, cytoplasmic 2 (ACTG) & 2608 & -5.06 & $<0.05$ & 59 & 50 & $42.1 / 5.31$ & $41.0 / 5.76$ & 13 & $4 / 6(66 \%)$ \\
\hline $\begin{array}{l}\mathrm{P} 06753 \\
071136\end{array}$ & Tropomyosin alpha-3 chain (TPM3) & 2740 & -2.07 & $<0.05$ & 65 & 65 & $32.8 / 4.68$ & $33.0 / 4.85$ & 20 & $6 / 13(46 \%)$ \\
\hline$\frac{071036}{P 68363}$ & $\begin{array}{l}\text { Tubulin alpha-1A chain (TBA1A) } \\
\text { Tubulin alpha-1B chain (TBA1B) }\end{array}$ & $\frac{2320}{2320}$ & -2.26 & \begin{tabular}{|l|l|}
$<0.02$ \\
$<0.02$ \\
\end{tabular} & $\frac{140}{140}$ & $\frac{40}{40}$ & $\begin{array}{l}50.7 / 4.94 \\
50.84 .94\end{array}$ & $60.0 / 5.31$ & 35 & $\begin{array}{l}10 / 16(62.5 \%) \\
10 / 16(6.5 \%)\end{array}$ \\
\hline \multicolumn{11}{|c|}{ Tubulin alpha-1B chain (TBA1B) } \\
\hline $\begin{array}{l}\mathrm{P} 60174 \\
\end{array}$ & Triosephosphate isomerase (TPIS) & 2843 & -2.44 & $<0.05$ & 54 & 100 & $26.9 / 6.45$ & $28.0 / 6.49$ & - & - \\
\hline \multicolumn{11}{|c|}{$\begin{array}{l}\text { Molecular chaperones/heat shock protein } \\
\text { Po101 }\end{array}$} \\
\hline P30101 & Protein disulfide-isomerase A3 (PDIA3) & 2337 & -2.75 & $<0.001$ & 194 & 50 & $57.1 / 5.98$ & $59.0 / 6.06$ & 33 & $14 / 17(82 \%)$ \\
\hline & Protein disulfide-isomerase A6 (PDIA6) & 2413 & -2.07 & $<0.01$ & 74 & 50 & $48.4 / 4.95$ & 53.015 .28 & 15 & $5 / 7(71 \%)$ \\
\hline $\begin{array}{l}\text { Transport } \\
\text { P02774 }\end{array}$ & Vitamin D-binding protein (VTDB) & 2317 & -2.68 & $<0.05$ & 163 & 50 & $54.5 / 5.40$ & $55.0 / 5.33$ & 32 & $12 / 19(63 \%)$ \\
\hline
\end{tabular}
MS/MS.

Seven pairs of matched spots identified in both subtypes corresponded to nine different proteins. The match is important to confirm the comparative analysis performed by the software. Six spots representing albumin were identified, but not considered in the differentially expressed group. Two proteins showed unreliable values of $\mathrm{MM}(\Delta \mathrm{MW}>20 \%)$ and were not considered in our analysis. One spot (834) was identified positively only in IDC, the corresponding spot (2575) in the ILC master gel exhibited low peptide volume and was not identified by MS. Despite the standard methodological control, the difference may be a result of main biological changes between the two histological subtypes.

Ten upregulated proteins were identified in the IDC group (Table 2), nine of them were confirmed to be downregulated in the ILC samples (Table 3). The images of the reference gels from each subtype (Figures 1 and 2) show the 10 successfully identified proteins labeled according to the protein identity in MASCOT database. Cytoplasmic actin 1 and 2 (ACTB/G), tropomyosin alpha-3 chain (TPM3), tubulin alpha-1A chain (TBA1A), tubulin alpha-1B chain (TBA1B), vimentin (VIME), triosephosphate isomerase (TPIS), protein disulfide-isomerase A3 (PDIA3), protein disulfide-isomerase A6 (PDIA6), and vitamin D-binding protein (VTDB) were identified with increased expression levels in IDC samples.

Proteins were identified and classified based on their main biological function (PucciMinafra et al., 2006), as structural proteins, metabolic enzymes, molecular chaperones/heat-shock proteins, binding proteins, or transport proteins. 


\section{Structural proteins}

Six structural proteins were found to be upregulated in IDC: ACTB, ACTG, TPM3, TBA1A, TBA1B, and VIME. Most of them are related to cytoskeleton organization, as well as many other cellular processes. These proteins show increased expression in breast tumors, compared to matched non-tumor tissue (Pucci-Minafra et al., 2007).

Actins $B$ and $G(A C T B / G)$ had a 5.06-fold higher expression in IDC. These highly conserved proteins are widely distributed in all eukaryotic cells and essential for cell migration and division, when the cytoskeleton is dynamically redesigned (Pucci-Minafra et al., 2006; Guo et al., 2013). Nowak et al. (2005) have shown that the expression of actin is higher in invasive than in noninvasive carcinoma cells. In addition, some studies suggest a relation between actin organization and differential isoform expression on one hand and the ability of the tumor cells to metastasize on the other hand (Pucci-Minafra et al., 2007; Guo et al., 2013). The ACTB protein is deregulated in several cancers such as liver, melanoma, renal, colorectal, gastric, pancreatic, esophageal, lung, breast, prostate, and ovarian cancers, as well as in leukemia and lymphoma (Guo et al., 2013). This suggests that actins are involved in cancer pathogenesis, invasiveness, and metastasis. Our study demonstrates that actins are also differentially expressed in IDC and ILC, suggesting that their involvement is also variable among breast cancer subtypes.

Tropomyosins are microfilament-associated structural proteins. TPM3 had a 2.07-fold higher expression in IDC. Several studies have reported increased or decreased expression of different tropomyosin isoforms in a number of human solid tumors (Pawlak et al., 2004; Kim et al., 2008), even though the functional significance of the differential expression is unclear. Franzen et al. (1996) initially suggested that the absence of tropomyosin in tumor cells might reduce the stability of actin microfilaments because of a higher susceptibility to depolymerization. Li et al. (2006) demonstrated that the expression of specific isoforms of TPM is reduced in primary breast tumors in contrast to in metastatic tumors. By comparing the RNA level (using RT-qPCR) of TPMs between IDC and nontumor breast tissue, we observed that TPM3 was upregulated in IDC (Carvalho, 2013). This suggests that the upregulation of TPM3 may be a marker of the IDC subtype.

The alpha-tubulin microtubule proteins were 2.26-fold higher expressed in IDC samples. Studies have demonstrated that taxane sensitivity is correlated to the balance between the levels of polymerized tubulin in normal vs tumor tissue (Dozier et al., 2003). On the other hand, preliminary clinical studies have demonstrated that beta-tubulin shows a positive response to taxane, suggesting that the overexpression of beta-tubulin would be predictive to a positive response to this drug (Cortesi et al., 2009).

VIME expression is 4.69-fold higher (score 188 and $79 \%$ matched peptides) in IDC. VIME is a marker of mesenchymal differentiation, which occurs during epithelial-mesenchymal transition, a process that plays an important role in carcinogenesis by inducing cell dissemination, invasive motility, as well as drug resistance (Lehtinen et al., 2013; Ulirsch et al., 2013) as assigned by $\mathrm{He}$ et al. (2011) who found VIME overexpression in $90.5 \%$ of grade III breast carcinomas. Notably, immunohistochemical profiling by Domagala et al. (1993) suggests that the absence of VIME expression is more frequently associated to ILC than to IDC. Our findings corroborate these results and indicate the biological differences among these subtypes.

\section{Metabolic enzymes}

TPIS had a 2.44-fold higher expression in IDC when compared to ILC (60\% coverage). 
TPIS is an enzyme involved in gluconeogenesis, glycolysis, and triglyceride synthesis. Cortesi et al. (2009) investigated markers of chemotherapy response by looking at secreted proteins in tumor interstitial fluid and non-tumor tissue from patients with breast cancer, and they observed an increase in TPIS expression in patients with a good response to therapy. In conclusion, high levels of this protein may be predictive of therapy response and emphasize the possibility of inducing the metabolic stimulation as a therapeutic approach.

\section{Molecular chaperones/heat-shock proteins}

In this functional class, we increased expression of PDIA3 and PDIA6 (isoform-2) by 2.75 -fold $(P<0.001)$ and 2.07 -fold $(P<0.01)$, respectively, in IDC compared to ILC. PDIA3 and PDIA6 are members of the heat-shock protein family that act as chaperones in the endoplasm reticulum stress signaling pathway and are involved in protection against oxidative stress (Pressinotti et al., 2009). The overexpression of these proteins in IDC may be the result of a compensatory mechanism in hypoxic conditions and during oxidative stress. We also confirmed the increased expression of the PDIA3 gene in IDC compared with normal breast tissue $(P<0.001)$ by RT-qPCR and found differential expression of both genes in more aggressive tumor subsets, such as in lymph node metastasis and grade III tumors (Ramos et al., 2015). A comparative proteomic study of breast tumors and adjacent normal tissue also showed increased expression of PDIA3 and PDIA6 proteins in breast carcinoma (Alldridge et al., 2008). Pressinotti et al. (2009) investigated the differential expression of PDIA3 in prostate cancers. According to their study, PDIA3 plays an important role in prostate tumor tissue as a pro-apoptotic factor. To our knowledge, it is the first time that the expression difference between ILC and IDC is presented.

\section{Transport}

We found a significant differential expression (2.68-fold increase) of the VTDB in IDC samples. In vitro studies have revealed that the binder of VTDB is involved in proliferation signaling, differentiation, and survival of normal epithelial mammary cells (Welsh, 2007). High levels of these receptors are found in $80 \%$ of breast tumors, in comparison with normal breast tissue (Pawlik et al., 2006). In addition, the deregulation of vitamin $D$ signaling is associated with cell proliferation and transformation (McCullough et al., 2009).

In conclusion, we explored the differential proteomic profile of ductal and lobular carcinomas using 2-DE and MS. Despite the limited sample size, we performed standard methods for the comparative analysis of complex and heterogeneous samples. Strikingly, our results confirmed the differential expression of 10 proteins reported as relevant in a range of breast cancer studies. Further comparisons with transcriptomic and genomic investigations showed a poor correlation between the results obtained. The distinct methodologies (MS, microarray, and CGH) used by different authors are quite variable (Zhao et al., 2004; Bertucci et al., 2008) and the identified biomarkers do not overlap. This fact reinforces the importance of applying a proteomic approach, as presented here, in order to expand our biological and molecular understanding of breast cancer. The proteins identified here represent promising candidate biomarkers for the identification and differentiation of the histological phenotypes of IDC and ILC. 


\section{ACKNOWLEDGMENTS}

The authors are thankful to the Department of Biochemistry of Federal University of Paraná for providing the MALDI-TOF, and Dr. Roseli Wassem for the valuable technical suggestions. Research partially supported by CNPq, grant \#473211/2007-6.

\section{REFERENCES}

Alldridge L, Metodieva G, Greenwood C, Al-Janabi K, et al. (2008). Proteome profiling of breast tumors by gel electrophoresis and nanoscale electrospray ionization mass spectrometry. J. Proteome Res. 7: 1458-1469.http://dx.doi.org/10.1021/ pr7007829

Bertucci F, Orsetti B, Nègre V, Finetti P, et al. (2008). Lobular and ductal carcinomas of the breast have distinct genomic and expression profiles. Oncogene 27: 5359-5372.http://dx.doi.org/10.1038/onc.2008.158

Berx G, Cleton-Jansen AM, Nollet F, de Leeuw WJ, et al. (1995). E-cadherin is a tumour/invasion suppressor gene mutated in human lobular breast cancers. EMBO J. 14: 6107-6115.

Bradford MM (1976). A rapid and sensitive method for the quantitation of microgram quantities of protein utilizing the principle of protein-dye binding. Anal. Biochem. 72: 248-254.http://dx.doi.org/10.1016/0003-2697(76)90527-3

Carvalho CS (2013). Análise da expressão gênica de tropomiosinas em carcinomas mamários. Master's thesis. UFPR, Curitiba, PR.

Chen YY, Lin SY, Yeh YY, Hsiao HH, et al. (2005). A modified protein precipitation procedure for efficient removal of albumin from serum. Electrophoresis 26: 2117-2127.http://dx.doi.org/10.1002/elps.200410381

Colantonio DA, Dunkinson C, Bovenkamp DE and Van Eyk JE (2005). Effective removal of albumin from serum. Proteomics 5 : 3831-3835.http://dx.doi.org/10.1002/pmic.200401235

Cortesi L, Barchetti A, De Matteis E, Rossi E, et al. (2009). Identification of protein clusters predictive of response to chemotherapy in breast cancer patients. J. Proteome Res. 8: 4916-4933.http://dx.doi.org/10.1021/pr900239h

Domagala W, Markiewski M, Kubiak R, Bartkowiak J, et al. (1993). Immunohistochemical profile of invasive lobular carcinoma of the breast: predominantly vimentin and p53 protein negative, cathepsin $\mathrm{D}$ and oestrogen receptor positive. Virchows Arch. A Pathol. Anat. Histopathol. 423: 497-502.http://dx.doi.org/10.1007/BF01606541

Dozier JH, Hiser L, Davis JA, Thomas NS, et al. (2003). $\beta$ class II tubulin predominates in normal and tumor breast tissues. Breast Cancer Res. 5: R157-R169.http://dx.doi.org/10.1186/bcr631

Dupont A, Corseaux D, Dekeyzer O, Drobecq H, et al. (2005). The proteome and secretome of human arterial smooth muscle cells. Proteomics 5: 585-596.http://dx.doi.org/10.1002/pmic.200400965

Franzén B, Linder S, Uryu K, Alaiya AA, et al. (1996). Expression of tropomyosin isoforms in benign and malignant human breast lesions. Br. J. Cancer 73: 909-913.http://dx.doi.org/10.1038/bjc.1996.162

Guo C, Liu S, Wang J, Sun MZ, et al. (2013). ACTB in cancer. Clin. Chim. Acta 417: 39-44.http://dx.doi.org/10.1016/j. cca.2012.12.012

Hanby AM (2005). Aspects of molecular phenotype and its correlations with breast cancer behaviour and taxonomy. Br. J. Cancer 92: 613-617.http://dx.doi.org/10.1038/sj.bjc.6602421

Hanby AM and Hughes TA (2008). In situ and invasive lobular neoplasia of the breast. Histopathology 52: 58-66.http://dx.doi. org/10.1111/j.1365-2559.2007.02891.x

He J, Shen D, Chung DU, Saxton RE, et al. (2009). Tumor proteomic profiling predicts the susceptibility of breast cancer to chemotherapy. Int. J. Oncol. 35: 683-692.

He J, Whelan SA, Lu M, Shen D, et al. (2011). Proteomic-based biosignatures in breast cancer classification and prediction of therapeutic response. Int. J. Proteomics 2011: 896476.http://dx.doi.org/10.1155/2011/896476

Kim TM, Yim SH, Shin SH, Xu HD, et al. (2008). Clinical implication of recurrent copy number alterations in hepatocellular carcinoma and putative oncogenes in recurrent gains on 1q. Int. J. Cancer 123: 2808-2815.http://dx.doi.org/10.1002/ ijc. 23901

Laemmli UK (1970). SDS-PAGE. Nature 227: 680-685.http://dx.doi.org/10.1038/227680a0

Lehtinen L, Ketola K, Mäkelä R, Mpindi JP, et al. (2013). High-throughput RNAi screening for novel modulators of vimentin expression identifies MTHFD2 as a regulator of breast cancer cell migration and invasion. Oncotarget 4: 48-63.http:// dx.doi.org/10.18632/oncotarget.756

Li Cl, Daling JR, Malone KE, Bernstein L, et al. (2006). Relationship between established breast cancer risk factors and risk of seven different histologic types of invasive breast cancer. Cancer Epidemiol. Biomarkers Prev. 15: 946-954.http://dx.doi. 
org/10.1158/1055-9965.EPI-05-0881

McCullough ML, Bostick RM and Mayo TL (2009). Vitamin D gene pathway polymorphisms and risk of colorectal, breast, and prostate cancer. Annu. Rev. Nutr. 29: 111-132.http://dx.doi.org/10.1146/annurev-nutr-080508-141248

Milioli HH, Santos Sousa K, Kaviski R, Dos Santos Oliveira NC, et al. (2015). Comparative proteomics of primary breast carcinomas and lymph node metastases outlining markers of tumor invasion. Cancer Genomics Proteomics 12: 89-101.

Nowak D, Skwarek-Maruszewska A, Zemanek-Zboch M and Malicka-Błaszkiewicz M (2005). Beta-actin in human colon adenocarcinoma cell lines with different metastatic potential. Acta Biochim. Pol. 52: 461-468.

Pawlak G, McGarvey TW, Nguyen TB, Tomaszewski JE, et al. (2004). Alterations in tropomyosin isoform expression in human transitional cell carcinoma of the urinary bladder. Int. J. Cancer 110: 368-373.http://dx.doi.org/10.1002/ijc.20151

Pawlik TM, Hawke DH, Liu Y, Krishnamurthy S, et al. (2006). Proteomic analysis of nipple aspirate fluid from women with earlystage breast cancer using isotope-coded affinity tags and tandem mass spectrometry reveals differential expression of vitamin D binding protein. BMC Cancer 6: 68.http://dx.doi.org/10.1186/1471-2407-6-68

Pressinotti NC, Klocker H, Schäfer G, Luu VD, et al. (2009). Differential expression of apoptotic genes PDIA3 and MAP3K5 distinguishes between low- and high-risk prostate cancer. Mol. Cancer 8: 130.http://dx.doi.org/10.1186/1476-4598-8-130

Pucci-Minafra I, Cancemi P, Fontana S, Minafra L, et al. (2006). Expanding the protein catalogue in the proteome reference map of human breast cancer cells. Proteomics 6: 2609-2625.http://dx.doi.org/10.1002/pmic.200500627

Pucci-Minafra I, Cancemi P, Marabeti MR, Albanese NN, et al. (2007). Proteomic profiling of 13 paired ductal infiltrating breast carcinomas and non-tumoral adjacent counterparts. Proteomics Clin. Appl. 1: 118-129.http://dx.doi.org/10.1002/ prca. 200600334

Ramos FS, Serino LTR, Carvalho CMS, Lima RS, et al. (2015). PDIA3 and PDIA6 gene expression as an aggressiveness marker in primary ductal breast cancer. Genet. Mol. Res. 14: 6960-6967.http://dx.doi.org/10.4238/2015.June.26.4

Sutton CW, Rustogi N, Gurkan C, Scally A, et al. (2010). Quantitative proteomic profiling of matched normal and tumor breast tissues. J. Proteome Res. 9: 3891-3902.http://dx.doi.org/10.1021/pr100113a

Tang Y, Mackey J, Lai R, Ghosh S, et al. (2013). Quantitative proteomic analysis of HER2 normal and overexpressing MCF-7 breast cancer cells revealed proteomic changes accompanied with HER2 gene amplification. J. Proteomics 91: 200-209. http://dx.doi.org/10.1016/j.jprot.2013.06.034

Traub F, Feist H, Kreipe HH and Pich A (2005). SELDI-MS-based expression profiling of ductal invasive and lobular invasive human breast carcinomas. Pathol. Res. Pract. 201: 763-770.http://dx.doi.org/10.1016/j.prp.2005.08.011

Ulirsch J, Fan C, Knafl G, Wu MJ, et al. (2013). Vimentin DNA methylation predicts survival in breast cancer. Breast Cancer Res. Treat. 137: 383-396.http://dx.doi.org/10.1007/s10549-012-2353-5

Welsh J (2007). Targets of vitamin D receptor signaling in the mammary gland. J. Bone Miner. Res. 22 (Suppl 2): V86-V90. http://dx.doi.org/10.1359/jbmr.07s204

Westermeier R and Naven T (2002). Proteomics in practice: A laboratory manual of proteome analysis. In part II: Course manual, Step 9: In-gel digestion. Wiley-VCH, p.261.

Whelan SA, He J, Lu M, Souda P, et al. (2012). Mass spectrometry (LC-MS/MS) identified proteomic biosignatures of breast cancer in proximal fluid. J. Proteome Res. 11: 5034-5045.http://dx.doi.org/10.1021/pr300606e

Zhao H, Langerød A, Ji Y, Nowels KW, et al. (2004). Different gene expression patterns in invasive lobular and ductal carcinomas of the breast. Mol. Biol. Cell 15: 2523-2536.http://dx.doi.org/10.1091/mbc.E03-11-0786

Zolotarjova N, Martosella J, Nicol G, Bailey J, et al. (2005). Differences among techniques for high-abundant protein depletion. Proteomics 5: 3304-3313.http://dx.doi.org/10.1002/pmic.200402021 